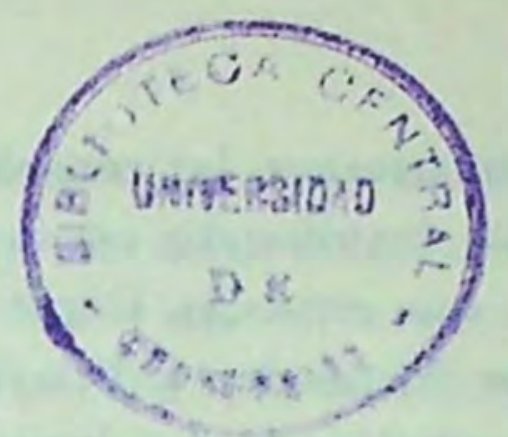

Raúl Silva Castro

\title{
Menéndez y Pelayo ante la literatura chilena ${ }^{(*)}$
}

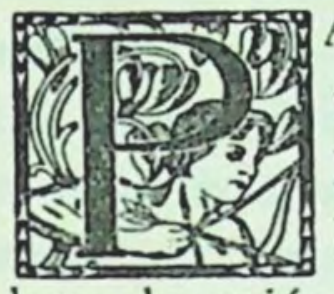

ARA conmemorar el cuarto centenario del descubrimiento de América, que se cumplía el 12 de octubre de 1892, la Real Academia Española discurrió formar una antología de la poesía hispanoamericana que establecería un lazo de unión constante entre los pueblos hablantes de un mismo idioma y la madre patria en que este idioma fué creado y dotado de sus más permanentes caracteres. La empresa fué encomendada al académico don Marcelino Menéndez y Pelayo. ¿Era el más adecuado y competente para llevarla a buen término? Sin duda. Así lo prueba el resultado que obtuvo, en una obra que sigue siendo consultada con fruto por cuantos tenemos en algún grado la pretensión de estudiar la historia literaria del continente o ahondar en una fracción nacional de la misma. Pero lo prueba asimismo el peso crítico que adquieren las opiniones del docto escritor, a poco que se las examine en presencia de las obras que les dieron origen. Y terminan también de probarlo las muchas relaciones que a esas alturas de la vida había conquistado Menéndez y Pelayo, a la distancia, entre los principales escri-
\end{abstract}

(*) Fragmentos de una conferencia leída el 17 de octubre de 1956 en la Universidad Católica de Santiago, Chile. 
tores americanos, las consultas que les envió, el género de la curiosidad que manifestaba en su correspondencia literaria, nunca más prodigada que entonces. Con todo este caudal a la vista, podemos asegurar que Menéndez y Pelayo cumplió sobradamente el propósito que había guiado a la Academia, y que por lo tanto la elección fué acertada y feliz.

Para entenderlo así nos habrá de ser permitido recapitular a grandes rasgos qué fué Menéndez y Pelayo en la España de su época y cuáles eran los títulos que atesoraba hacia 1892 para ser distinguido con el encargo de que acabamos de hablar.

Menéndez y Pelayo tuvo una vida corta. Nació y murió en su "Cantabria invicta", y desde mozo hubo de distinguírsele en el seno de la familia y entre los muchachos de la escuela y del Instituto, por la rara comezón de estudiar que le dominaba. A los catorce años el joven disertaba en latín sobre la inmortalidad del alma, y es posible que en sus proposiciones se juntaran la seguridad de la forma y la disciplina de los conceptos. A los dieciocho obtenía el grado de licenciado después de exámenes brillantes; el año siguiente era recibido como doctor en letras. ¿Cabe precocidad más insigne? Pero ella en sí misma tenía su precio. Para llegar al profesorado universitario, única carrera abierta a dotes tan portentosas, era preciso, según ley entonces vigente en España, contar veinticinco años de edad. La ley no se había puesto en el caso de que un hombre lograra, en pleno equilibrio de sus facultades, abreviar las etapas y alcanzar, antes de los veinte años, los títulos que era preciso adquirir tras serias pruebas y difíciles estudios. Y Menéndez y Pelayo hubo de esperar.

Empleó tres años de la espera en recorrer bibliotecas de países extranjeros, principalmente Italia y Francia, en busca de informaciones para los libros que tenía proyectado escribir y para completar sus conocimientos. Podría asegurarse que había leído cuanto en España las bibliotecas tenían de interés para sus estudios. A los veintidós años ya era cruel prolongar por más tiempo este compás, que en áltimo término significaba arrebatar a la cátedra una capacidad intelectual de primer orden, y entonces se dictó una reforma de la ley 
que permitiría a Menéndez y Pelayo cumplir el trámite que le faltaba para incorporarse al profesorado. Tales son los extraordinarios comienzos del joven santanderino. Los años siguientes no son menos extraordinarios, si se advierte que las obras fueron acumulándose en su escritorio, que perteneció a varias academias y que al fallecer el 19 de mayo de 1912, antes de cumplir cincuenta y seis años de edad, había realizado una labor que no es exagerado llamar titánica.

En Barcelona fué discípulo de Milá y Fontanals, el mejor maestro que podía tener, y no cabe dudar de que ello decidió el rumbo que iba a imprimir a sus estudios. Milá y Fontanals, como puede apreciarse por el carácter de sus escritos, era un erudito serio y recogido que había ido poniendo, con regularidad metódica, los cimientos de una amplísima revisión de los conceptos entonces vigentes sobre la historia de la literatura española. Para ello debió ensanchar sus investigaciones a las letras provenzales y escribir multitud de monografías útiles. Menéndez y Pelayo se propuso cosa semejante, y más de una vez habló del proyecto de historia general de la literatura de su patria que tenía pensado. No lo realizó, por desdicha para la cultura españoia, y se entretuvo en preliminares y en estudios parciales y monográficos, aun cuando en todos ellos es fácil discernir no sólo la trabazón orgánica con que se iban presentando al escritor, sino también encontrar vistas generales que señalan hasta qué punto se hallaba ya el espíritu de Menéndez y Pelayo maduro para la obra cumbre que de él quedamos esperando. Y pues no tenemos la "historia”, detengámonos en las "historias" que completó y dió a luz.

La primera, cronológicamente hablando, es La Ciencia Española (1878), fogoso alegato del patriota y del hombre de fe. España tuvo su hora de esplendor y en ella dominó el mundo conocido, conquistó uno nuevo y difundió por todo el orbe su lengua y su religión. Empresa tan audaz debía tener su rescate y el que se proporcionó a España raya todos los extremos de la injusticia. Cuando la nación conquistadora, colonizadora y civilizadora por excelencia hubo de rendirse al peso de los propios excesos de su vitalidad, es decir, cuando sonó para ella la hora de la inevitable decadencia, miles de cuer- 
vos graznadores dejáronse caer sobre la exangüe España. Proliferaron entonces las leyendas y se hizo escarnio de la historia española. Un inconsciente dijo que en España no había habido ciencia y algunos descastados tradujeron aquello y lo repartieron por el mundo entero, con siniestra satisfacción. Tal es, a grandes rasgos, el estado de las cosas en el momento en que la pluma de Menéndez y Pelayo escribió ese fogoso libro juvenil con el cual se propone demostrar que España tuvo en su hora de esplendor tanta ciencia como cualquier otro pueblo de su tiempo. ¿Y quién que lea las páginas espléndidas de ese libro publicado a los veintidós años de edad, se atreverá a seguir sosteniendo la tesis de M. Masson de Morvilliers?

Pero el buen don Marcelino traía de su áspera Cantabria una cabeza dura, y como la acogida tempestuosa que encontró su Ciencia Española no le bastara, comenzó en 1880 a publicar la Historia de los heterodoxos españoles, a la cual dió cima, en su primera edición, en 1886. Otra obra polémica, de información abundantísima, pero también otro capítulo para la historia de la literatura de su patria. ¿Es posible desde esos años escribir de las letras españolas sin acudir a cada paso a don Marcelino? En 1881 lee las conferencias que forman su volumen sobre Calderón y el propio año comienza a publicar su Historia de las ideas estéticas en España, terminada en 1891. La Real Academia Española, a la cual se incorporó leyendo un admirable discurso sobre la poesía mística, le encarga publicar las obras de Lope de Vega, y el erudito hace sin quererlo ostentación de sus conocimientos en unos prólogos que se leen con avidez por lo mucho que dicen de Lope, del teatro de su tiempo, de la historia de España y de cuantos fenómenos puedan interesar al estudioso de las letras. En 1890 inicia la serie de volúmenes que componen su Antología de poetas líricos castellanos, terminada en 1906, y en 1905 da a luz los Origenes de la Novela. No se necesita más para ponerle a la cabeza de todos los eruditos españoles de su siglo y de todos los siglos. Pero hay más, porque existen Horacio en España (1877, con segunda edición en 1885), la Antología de poetas hispanoamericanos y multitud de otros escritos menores, cada uno de los cuales tiene méritos pro- 
pios, porque muestra algo del vasto tesoro intelectual que señoreaba el autor.

$\mathrm{Y}$ estos libros, que pudieron ser eruditos si por tal se entiende secos de estilo, podestres, apegados a la letra de los documentos y nivelados por el rasero de la mera utilidad científica, están todos escritos con brío, con interés y con emoción por un hombre apasionado de la inteligencia y del saber, que ponía el arte por encima de todo y que no renunciaba a la legítima aspiración de escribir con tersura, elegancia y elocuencia. El escritor no necesita divagar para elevar el tono a la altura de su tema, cuando el caso lo requiere, y su obra toda es la mejor prueba de que es posible, como pedía el uruguayo Rodó, "decir las cosas bien”, aun cuando esas cosas pertenezcan al arduo y remontado mundo de la erudición literaria e histórica.

La crítica literaria española no conocía entonces esa alianza de saber y belleza, y fué preciso que Menéndez y Pelayo la propugnara con la fuerza avasalladora de su ejemplo para que en los años siguientes vinieran a parecer indisolubles las bellas formas y el examen que constituye la médula misma del ejercicio crítico. La muestra más feliz de esta fusión se encuentra en los discursos académicos, de los cuales hubo el maestro de pronunciar muchos debido a que las doctas corporaciones de su patria le abrieron las puertas en una edad a la cual los escritores, por regla general, comienzan apenas a mostrar las fuerzas en tímidos ensayos y tanteos. Quien lea hoy el discurso pronunciado por don Marcelino en su acto de incorporación a la Real Academia de la Lengua, no necesita más para saber cuanto le es preciso sobre la poesía mística, fenómeno el más descollante de la literatura española y que no encuentra par en la historia de ésta sino en la caudalosa creación anónima del Romancero.

La amenidad propia del discurso no puede, claro está, rayar a la misma altura cuando el autor acomete otras empresas en las cuales la erudición alcanza una parte mayor. Quien lea la Historia de las Ideas Estéticas no debe esperar verse deleitado a cada momento por la cadencia de la frase ni por el fuego de argumentos que distinguía al más ilustre crítico español de todos los tiempos; y, sin embargo, 
allí hay también fragmentos de antología y pasajes en los cuales la prosa corre con ejemplar limpidez y con tersura y gracia singulares. Cosa semejante cabe decir de la Antología de poetas líricos casta llanos, vasta empresa que ocupó dieciséis años de vida a su infatigable autor (1890-1906). Se trataba de disponer por orden cronológico el repertorio de la antigua poesía española y de ofrecer en un solo conjunto las más selectas muestras de la poesía lírica de la lengua. Tarea de esta categoría pudo pasar por sí sola como abrumadora para cualquier erudito que no poseyera el don de hacer las cosas bien, agotando la materia, atreviéndose con las mayores dificultades. Pero Menéndez y Pelayo quiso hacer e hizo mucho más. Escribió densos y prolijísimos prólogos en los cuales vertió las muchas nociones que había atesorado sobre la obra de los principales poetas de su patria, y hay volúmenes de esa serie en los cuales el prólogo invade todas las páginas. En conjunto, aquellas introducciones trazan la historia de la poesía lírica de la lengua castellana medieval en forma perfecta, y las monografías que en detalles han rectificado algunas de las afirrnaciones hechas por Menéndez y Pelayo, o completado noticias que a éste no alcanzaron, nc son todavía suficientes para aseverar que el libro haya perdido nada de su original frescura ni el carácter de irreemplazable instrumento de consulta que ha tenido y tiene.

La admirable lucidez que asistió al autor de tantos trabajos críticos puede poseer muchas fuentes que no es del dominio del hombre explicar con la claridad necesaria. Leyó incesantemente y leyó con método instintivo. Una atención indeficiente le permitió relacionar sus lecturas para trazar los cuadros de la historia de las letras de su patria que llevaba en la mente y que, como ya dijimos, no pudo completar. Y puesto a escribir, las nociones acudían a su memoria privilegiada, sin que se extraviara el juicio, sin que fallaran los principios del buen gusto que le habían servido de alimento primero y a los cuales, finalmente, prestó servicio con esmeradísimo amor.

Pero si no nos es permitido asomarnos al secreto del funcionamiento cerebral del crítico por antonomasia de las letras españolas, nos queda accesible lo que él mismo declaró sobre los cimientos de 
su buen gusto. En plano de confidencias exclamó un día: "En arte, soy pagano hasta los huesos". ¿Y qué obra hay de él que no pruebe la verdad de este aserto? En plena juventud había llenado papeletas de unos "solaces bibliográficos" que pronto tuvieron forma de libro y entonces nació el Horacio en España, que editado y corregido para la segunda edición salió de nuevo en 1885 a probarnos que en realidad era el arte pagano el que mejor satisfacía sus gustos. La Historia de las Ideas Estéticas es, por lo demás, una nueva prueba de esta afición declarada e irresistible que cantó en verso al decir:

\section{Yo guardo con amor un libro viejo...}

Con el nombre de "arte pagano" designaba don Marcelino las obras de la antigüedad greco-latina, que había estudiado hasta aprenderlas de memoria en los años de preparación inicial y a las cuales volvió, maduro ya para el ejercicio de la crítica, cada vez que le era necesario renovar el contacto con las fuentes de la cultura mediterránea de que la de su patria forma una provincia. Y como las conoció por dentro y por fuera, como erudito y también como mero gustador, siempre tuvo de ellas una noción cabal que le permitía atinar al manejarlas como cartabón para el estudio de las letras más modernas. Esos eran los modelos, y las obras de siglos más próximos eran tanto más perfectas o agradables cuanto más parecían ser trasuntos del modelo inmarcesible. Y he aquí cómo el católico a machamartillo, cual le gustaba llamarse, suyo fundir el paganismo y el cristianismo cuando se trataba de arte y, particularmente, de letras, y supo además resistir con denodado fuego la pretensión de dar contenido docente a los frutos de la creación artística.

Se dirá que los chilenos no hemos salido bien parados del examen del crítico santanderino, cuando a éste le fué dado entrar a estudiar nuestra producción literaria, con vistas a su Antología de poetas hispanoamericanos, ya referida, que se convirtió después en Historia de la poesía hispanoamericana (1911). Es verdad, pero para entender el suceso será preciso también distinguir algo. Por ceñirse 
demasiado fielmente al criterio de jus soli, Menéndez y Pelayo dejó en Bolivia a Ventura Blanco Encalada, a quien nadie podría titular sino escritor chileno, y en Venezuela al ínclito Andrés Bello. Olvidó entonces Menéndez y Pelayo que ambos autores, después de haber recorrido algo de mundo, prefirieron abiertamente a Chile para hogar de sus estudios y de su sangre, y que más hicieron por la cultura chilena que por la de cualquier otra nación, inclusive las de sus respectivos nacimientos. En el caso concreto de Bello, a quien ciertamente aparecen dedicadas no pocas páginas de la obra, el crítico se ve obligado a señalar a cada paso cuál fué el alcance de su magisterio y en qué círculos se ejercitó su influencia. Refiriéndose juntamente a Bello y a Barralt, dejó establecido que de ellos no quedaron discípulos en Venezuela: "el primero - agrega- llevó su actividad literaria a Chile... la literatura venezolana, apartada totalmente de la severa disciplina de aquellos filólogos, se abrió a la licencia romántica, representada allí especialmente por Abigail Lozano y Maitín". Volviendo a Bello mismo, Menéndez y Pelayo reconoció ampliamente, y en el estilo vigoroso que le era consustancial, el magisterio que había traído a Chile. He aquí sus palabras. "Afortunadamente, Bello había ido a asentar su cátedra en un pueblo americano que, menos dotado de condiciones brillantes que cualquier otro, a todos aventaja en lo firme de la voluntad, en el sentido grave y maduro de la vida, en el culto de la ley, en el constante anhelo de la perfección y en la virtud del respeto. No llegó a educar poetas, porque la tierra no los daba de suyo, pero educó hombres y ciudadanos, y su espíritu continúa velando sobre la gran República, que por tantos años ha sido excepción solemne entre el tumulto y agitación estéril de las restantes hijas de España".

Menéndez y Pelayo asiente aquí que Bello en Chile "no llegó a educar poetas, porque la tierra no los daba de suyo", y este dictamen es de los que han corrido hasta hoy llevándonos, a los propios chilenos, a menospreciar lo que nuestros abuelos y nuestros padres entendieron por poesía chilena. Se nos permitirá decir que prevalece en aquellas palabras el juicio estético sobre el moral y social. Nos 
entenderíamos mejor si dijéramos que Chile no daba en aquellos días poetas excelsos, poetas cumbres, poetas capaces de hacer volver la cabeza a quien anduviera ocupado en el escrutinio de las mil formas que la poesía ha revestido en el discurrir de las edades, para admirar sólo las flores más aromosas y coloridas y los más sabrosos frutos. Pero si por poesía entendemos la emanación del alma nacional, la confesión ingenua y espontánea que el hombre hace de su concepto del mundo, el entusiasmo que le despiertan los héroes y los santos, las inquietudes del alma enamorada, las zozobras y angustias que se experimentan en la vida cotidiana, todo ello en forma escrita y con alguna ayuda del arte, no sería lícito decir que en Chile no se daban los poetas, bajo la tutela de Bello o de otro maestro, porque el pueblo mismo no era capaz de hacerlos nacer. En este sentido, debe permitírsenos, pues, rectificar al insigne crítico español, o por lo menos esclarecer la forma algo perentoria de su lenguaje.

Volviendo al criterio de jus soli, en virtud del cual Menéndez y Pelayo había excluído a Bello en el estudio de la literatura chilena, débese también señalar un curioso paralogismo que nos sale al paso en la Antología. He aquí sus palabras: "No pertenece a este lugar la apreciación de los méritos de aquel varón extraordinario a quien ya procuramos dar a conocer en el estudio relativo a Venezuela; Bello, como poeta, no pertenece a Chile; sus dos composiciones magistrales y características, la Alocución a la poesía, la Silva a la agricultura en la zona tórrida, estaban escritas y publicadas en Londres desde 1823 y 1825, respectivamente. En Chile hizo pocos versos y más bien traducidos que originales. En cambio, a la educación de Chile dedicó los frutos de la madurez de su entendimiento y de su cultura científica. Aquella República le debió el Código Civil, los Principios del Derecho de Gentes, la Gramática castellana, y con ella el inapreciable bien de la conservación de la integridad del idioma; los Principios de Ortología y Métrica, todavía no superados hasta hoy; la Filosofía del entendimiento, y con ella la propagación de las sabias y templadas enseñanzas de la psicología escocesa; la organización de la Universidad sobre el modelo de las de Inglaterra; y, domi- 
nándolo todo, un alto y severo espíritu de disciplina moral y jurídica, que ha sido el más duradero fruto de su enseñanza".

La autoridad crítica de Menéndez y Pelayo era y es muy elevada, y en ciertos sentidos no ha sido superada hasta hoy. A ello podemos atribuir el que subsista el juicio a que acabamos de dar lectura. La Alocución a la poesía y la Silva a la agricultura de la zona tórrida pueden ser todo lo que se quiera "magistrales y características", pero no son las únicas producciones de Bello en que el crítico puede emplear sus fuerzas, sin temer dilapidarlas en una empresa baldía. Si por característico se entiende, cual quiere el contexto, aquella obra en la que se han vertido hasta el agotamiento las fuerzas del autor, debe aceptarse que también son características de la idiosincrasia de Bello otras producciones que éste no pudo escribir sino en Chile. En ese número se hallan las traducciones. Unas, según consta, fueron iniciadas por Bello en Londres y completadas en Chile, y de otras, en que no cabe señalar fechas precisas, podemos tener la sospecha de que, escritas en Inglaterra, sólo fueron puestas en limpio, corregidas y pulimentadas en Santiago; pero de algunas más no cabe duda alguna acerca de que hubieron de ser compuestas en Chile, porque los poemas originales de que la traducción procede no se habían publicado antes de 1829. En este número se halla la famosa Oración por todos, a la cual, como se verá en seguida, Menéndez y Pelayo distingue con título de excepción. Para nuestro crítico, en fin, las gracias del poeta de juventud reverdecieron en la versión de poemas ajenos:

"Donde volvemos a encontrar al excelente poeta de otros tiempos es en sus traducciones e imitaciones. La edad y los áridos y constantes estudios habían podido resfriar su vida poética propia, que siempre fué menos ardiente que luminosa; pero, en cambio, le habían hecho comprender y sentir cada día mejor ia inspiración ajena, y penetrar en el secreto de los estilos más diversos. Gracias a eso, pudo un mismo hombre dar propia y adecuada vestimenta castellana a obras de inspiración tan diversa como el Rudens, de Plauto, y El Sardanápalo y el Marino Faliero, de Byron; El Orlando enamorado, de Bo- 
yardo; un fragmento de los Niebelungen, y varias fantasías y Orientales, de Víctor Hugo. En estas traducciones o adaptaciones Bello hizo milagros, y, atendiendo a algunas de ellas, sobre todo al largo fragmento del Sardanápalo y a los catorce cantos que dejó traducidos del poema de Boyardo refundido por el Berni, no se le puede negar la palma entre todos los traductores poéticos de la pasada generación literaria, que los tuvo excelentes en España y en América. Entrar en el mecanismo de estas versiones y compararlas con los originales, sería ciertamente tarea útil y fecunda en grandes enseñanzas de lengua y de versificación; pero aquí no podemos ni intentarla siquiera. Las de Víctor Hugo no son traducciones ni quieren serlo, sino imitaciones muy castellanizadas, en que Bello se apodera del pensamiento original y le desarrolla en nuestra lengua conforme a nuestros hábitos líricos, a las condiciones de nuestra versificación y a la idiosincrasia poética del imitador. $\mathrm{Y}$ esto lo consigue de tal modo, que una de esas imitaciones, la Oración por todos, es sabida de todo el mundo en América y estimada por muchos como la mejor poesía de Bello; la más humana, la más rica de afecto; y no hay español que habiendo leído aquellas estrofas melancólicas y sollozantes, vuelva a mirar en su vida el texto francés sin encontrarle notoriamente inferior. Habrá acaso error de perspectiva en esto: yo no lo sé, pero consigno el hecho como parte y como testigo. Lo mismo acontece con la titulada Moisés en el Nilo, "bella en francés (dice Caro), más bella, intachable en la versión castellana de Bello”. Y tratándose de versiones poéticas, el voto de don Miguel Antonio Caro me parece el primer voto de calidad de nuestra lengua".

Puede entenderse que es grave irreverencia la del modestísimo escritor americano que alza la vista hasta el crítico español por antonomasia y no para prodigar una vez más el elogio encendido y entusiasta, y que se da acaso prueba de mal gusto si se intentan reparos y distingos en esta hora de la celebración del centenario, la más cargada de significado en la historia de las relaciones literarias entre España y América, al través de Menéndez y Pelayo. Pero con reverencia o sin ella, lo que uno siente debe decirlo. Yo no puedo conve- 
nir en que se siga sosteniendo que lo más "característico" de la obra poética de Bello es la Alocución y la Silva, obras de juventud, en las cuales se advierten todos los titubeos del aprendiz; obras tal vez no traducidas de una lengua extraña, pero en todo caso inspiradas en una larga línea tradicional de elogio al campo, a la vida rústica y a los cultivos propios de la tierra; obras de calco y de remedo, en que se han introducido enumeraciones de batallas y de plantas y elogios de héroes y de patriotas americanos para dar la impresión del ambiente vernáculo, sin que el autor en momento alguno pueda contagiarnos con el hervor de su entusiasmo ni con el patetismo de su relato, porque ni hervor ni patetismo existen; obras, en fin, sin nervio, frías, producidas con cálculo y como mero compromiso escolar que el estudiante debe cubrir para pasar de un curso a otro. En esos prolongados ejercicios retóricos en que sin duda se ha extremado no poco el juego cerebral correspondiente al ritmo y a la rima, echamos de menos al hombre, al ciudadano, al amante, al padre de familia.

$\mathrm{Y}$ es significativo que la porción de la obra de Bello en que figura el poeta bajo estas advocaciones, haya quedado prácticamente inadvertida para Menéndez y Pelayo. Justo es lo que dice de Bello como traductor, y sobre todo la calificación de La oración por todos; pero falta algo. Falta decir que en aquella poesía de Hugo que el poeta caraqueño sintió como cosa propia, incorporó la naturaleza chilena en el ambiente que describía y que fué también esa naturaleza, con sus accidentes y menudencias inconfundibles, el escenario que el poeta buscó, ya maduro, para exponer en El proscrito una nueva fase de su fisonomía literaria. Es verdad que El proscrito quedó en el telar y no puede hablarse de él sino como esbozo, puesto que el autor no prosiguió la tarea emprendida; pero ello no quita que en esos versos hallemos una ingenuidad, un risueño abandono, un calor patético y una gracia que distan mucho de encontrarse en las enfadosísimas Alocución y Silva, que no habríamos removido del osario en que yacen si no nos hubiéramos encontrado con el juicio de Menéndez y Pelayo.

Afortunadamente hay en la opinión del crítico santanderino ex- 
presiones más ecuánimes sobre Bello y justo será consignarlas antes de pasar adelante. Como parecer global, por ejemplo, digno es de la reproducción aquí y en cualquier otro estudio semejante, la siguiente semblanza, que vale por un tratado:

"La gran figura literaria de este varón memorable basta por sí sola para honrar, no solamente a la región de Venezuela, que le dió cuna, y a la República de Chile, que le dió hospitalidad y le confió la redacción de sus leyes y la educación de su pueblo, sino a toda la América española, de la cual fué el principal educador: por enseñanza directa en la más floreciente de sus repúblicas; indirectamente y por sus escritos en todas las demás: comparable en algún modo con aquellos patriarcas de los pueblos primitivos, que el mito clásico nos presenta, a la vez filósofos y poetas, atrayendo a los hombres con el halago de la armonía para reducirlos a cultura y vida social, al mismo tiempo que levantaban los muros de las ciudades y escribían en tablas imperecederas los sagrados preceptos de la ley. Acerca de Bello se han compuesto libros enteros, no poco voluminosos, y aún pueden escribirse mucho más, porque no hay pormenor insignificante en su vida, ni apenas materia de estudio en que él no pusiese la mano. Sus timbres de psicólogo, de pedagogo, de jurisconsulto, de publicista, de gramático, de crítico literario, no han obscurecido (por raro caso) su gloria de poeta, vinculada, no en raptos pindáricos ni en creaciones muy originales, sino en unas cuantas incomparables traducciones y en un número todavía menor de fragmentos descriptivos de naturaleza americana, donde el estudio de la dicción poética llega a un grado de primor y perfección insuperables, y en los cuales renace la musa virgiliana de las Geórgicas para cantar nuevos frutos y nuevas labores y consagrar con su voz las vírgenes florestas del Nuevo Mundo".

La mayor parte del estudio que Menéndez y Pelayo dedica a la poesía chilena aparece ocupada por los poetas coloniales, a quienes encabeza Ercilla. El crítico no se oculta que hay aquí convenciones históricas que deben merecer atención especial; dicho de otro modo, que la realidad histórica de la literatura nacida en el suelo de Chile 
difiere no poco de la que se ofrece en otras de las provincias del antiguo imperio español. "Una tribu de bárbaros heroicos gastó allí los aceros y la paciencia de los conquistadores", de lo cual resulta que "la raza indígena, que tan escasa o nula influencia ha ejercido en la literatura hispanoamericana", alcanza en la porción chilena "una acción indirecta tan poderosa, que decide del género y asunto de la mayor parte de las producciones en prosa y en verso que allí durante dos siglos se compusieron". Y en resumen afirma: "Si aquellos bárbaros no escribían versos ni componían historias, y sólo conocían la poesía y la elocuencia en su formas más rudas y elementales, daban a lo menos continua ocasión, con las hazañas de su increíble resistencia, a que se multiplicasen los poemas y las historias de que ellos venían a ser héroes sin saberlo. Así se formó en tiempos plenamente históricos una literatura de temple muy épico, que contrasta con el carácter patriarcal y algo casero que las letras coloniales ofrecían por lo general en los pacíficos emporios de México y Lima, o en las escondidas metrópolis de Quito y Santa Fe. Y aun en cierto sentido puede decirse con don Andrés Bello que "Chile es el único de los pueblos modernos cuya fundación ha sido inmortalizada por un poema épico". Ni hay tampoco literatura del Nuevo Mundo que tenga tan noble principio como la de Chile, la cual empieza nada menos que con La Araucana, obra de ingenio español, ciertamente, pero tan ligada con el suelo que su autor pisó como conquistador y con las gentes que allí venció, admiró y compadeció a un tiempo, que sería grave omisión dejar de saludar de paso la noble figura de Ercilla, mucho más cuando su poema sirvió de tipo a todos los de materia histórica, compuestos en América, o sobre América, durante la época colonial".

En período más próximo a nosotros, estudia las producciones de Salvador Sanfuentes, en quien ve "una medianía elegante”, Hermógenes de Irisarri, Jacinto Chacón y Carlos y Francisco Bello, ambos hijos de don Andrés, Mercedes Marín de Solar, a quien elogia "la sinceridad lírica”, y del argentino Gabriel Real de Azúa. Como consecuencia de la estada de Bello en Chile, anota la creación de la Uni- 
versidad de Chile y subraya la influencia que ella había podido tener hasta 1892 en los estudios literarios. Y es aquí donde encontramos otra vez una de aquellas definiciones con las cuales se ha venido por años minorando el valer de la literatura chilena, aun cuando éste precisamente no haya podido ser el designio del ilustre crítico. "El carácter del pueblo chileno -escribía-, como el de sus progenitores, vascongados en gran parte, es positivo, práctico, sesudo, poco inclinado a idealidades. Esta limitación artística está bien compensada por excelencias más raras y más útiles en la vida de las naciones; pero hasta ahora es evidente e innegable. No pretendemos por eso que haya de durar siempre. Dios hace nacer el genio poético donde quiere y no hay nación ni raza que esté desheredada de este don divino. Los hombres, caros a las musas, de Eusebio Lillo, Guillermo Matta, G. Blest Gana, Eduardo de la Barra y otros poetas vivos aún, y que, por consiguiente, no deben ser aquí materia de nuestro estudio, son prenda de un porvenir que puede ser tan honroso para Chile como lo es el presente bajo otros respectos. Pero hoy por hoy todavía puede decirse que la cultura estética no ha echado raíces bastantes hondas en Chile; lo cual se comprueba, no sólo con la relativa escasez de su producción poética comparada con la de otras repúblicas hispanoamericanas, sino con el carácter árido y prolijo que se advierte en muchos escritos en prosa dignos de alabanza por su contenido; y con la falta de estilo y arte de exposición que en las mismas monografías históricas, que son el nervio de su literatura, desluce muchas veces los resultados de una labor sabia, paciente y honradísima".

Hasta aquí las observaciones son templadas y debidamente comprendidas dentro del momento histórico que las justifican, podrá aceptarlas quienquiera acepte que las cosas pueden cambiar con el tiempo, ya que Menéndez y Pelayo no podía hablar sino de lo que tenía ante los ojos y no se aventuraba a profetizar cosa alguna. Pero la observación que sigue es de carácter algo diferente. Oigamos su texto literal: "Chile, colonia secundaria durante la dominación española, tiene historias más largas que las de Roma por Mommsen, más largas que las de Grecia por Curtius o por Grote. Evidentemente es 
demasiado, y no basta todo el entusiasmo nacional para borrar la diferencia y para hacer interesante lo que de suyo no lo es".

Parece que el crítico estaba apuntando a la Historia general de Chile que lleva la firma de Diego Barros Arana y que, iniciada en 1884, alcanzó a completar dieciséis volúmenes en 1902. Y si es justa la inferencia, se nos permitirá disentir una vez más de su ilustrado juicio, dejando en claro que no ponemos un instante en duda la pureza de sus intenciones.

Cuando Grote y Curtius iniciaron las obras a que Menéndez y Pelayo alude, una legión de comentaristas y eruditos había intentado centenares de útiles monografías sobre las antigüedades griegas, y frondosas escuelas de filología clásica mantenían cátedras abiertas en las más importantes universidades europeas y principalmente en las alemanas. De todos esos centros partían estudios menores sobre personajes de la vida clásica de Grecia, sobre episodios de la historia civil de las ciudades y de las tribus griegas y acerca de usos, costumbres, artes e instituciones del mundo helénico. Curtius y Grote podían resumir y condensar estas adquisiciones en breves páginas, porque lo justo es que la monografía preceda al ensayo de síntesis. Mommsen, por su parte, evocado también por Menéndez y Pelayo en aquel juicio que tan peyorativo resulta para nuestra literatura, es verdad que había reducido la historia de Roma a menos páginas que las que materialmente cubría la obra cumbre de nuestro Barros Arana. Pero debe pensarse, para intentar el juicio comparativo, que Mommsen emprendió su tarea teniendo a la vista un completo y prolijo arsenal de memorias, crónicas y anales, en los que docenas de testigos deponían sus personales testimonios, y que a ese arsenal cada día acrecentado debe añadirse, para alcanzar la ecuanimidad en la apreciación, el fruto de las escuelas de antigüedades que ya hemos evocado en el caso del estudio de la historia griega. Dicho de otra suerte: aquellos historiadores podían intentar la síntesis en sus respectivas obras, porque la pesada y a veces ingrata labor de expurgación y de erudición estaba ya cumplida hasta el agotamiento por legiones de especialistas que les abreviaron el trabajo final. 
Se concederá que no era el caso nuestro y que si la Historia general de Chile que, al parecer, tenía el maestro santanderino a la vista se mostraba más extensa que las de Grecia y de Roma, ello se debe en gran medida al hecho de que Barros Arana al redactarla hubo de atender tanto al análisis como a la síntesis de los sucesos, y tuvo que ser, a un mismo tiempo, historiador y cronista. El tiempo corrido desde que se pronunció aquel juicio de Menéndez y Pelayo nos permite a nosotros, los de su posteridad, concluir en forma diametralmente opuesta.

Debe anotarse, eso sí, para ser justos, que el parecer de Menéndez y Pelayo tiene, como todas las cosas humanas en que entran el gusto y la opinión, una vigencia precaria, que acaso ya esté cumplida; y que, en fin, el error no está en él sino en quienes, a destiempo, repiten aquellas expresiones magistrales sin hacerles ninguna rebaja, sin apreciar siquiera el cambio que en ellas está llamado a producir el paso de los años, si alguno en realidad se ha producido. Entendiéndolo así, nosotros afirmamos la buena fe del crítico, defendemos ardientemente los motivos que tuvo para opinar como opinó y hasta repetiremos sus palabras cada vez que nos parezca necesario, sin otra condición que poner al lado la fecha en que fueron proferidas. La historia literaria ha venido allegando nuevas luces y comprobaciones útiles, y en presencia de ellas, Menéndez y Pelayo, el que lo leía todo, podemos asegurar que no diría hoy lo que entonces dijo. Y la mejor prueba de que así lo sentimos nos la da esta misma ceremonia hasta la cual hemos traído nuestra voz. Se trataba de relacionar en forma sucinta lo que el maestro había opinado de los escritores chilenos, en la ocasión solemne de su centenario, esto es, cuando todas las naciones cultas le señalan como profundo pensador, ilustrado crítico e historiador concienzudo y agudísimo, títulos todos por los cuales tiene ganada permanente adhesión al nombre de España como heraldo de sus empresas de asentamiento de la cultura occidental y de la fe cristiana en los pueblos del Nuevo Mundo. Disentir de un juicio suyo en materia tan menuda como es la literatura de una sola de las provincias de aquel imperio, no significa regatear en nada la 
grandeza del varón benemérito por cuyos ojos diligentes y por cuyas manos laboriosas pasó todo el inventario bibliográfico de las letras hispanas. A su sombra hemos crecido y a la distancia nos reconocemos sus discípulos. El amor a la verdad lo hemos heredado de él y en este amor reposamos para que se lleven con indulgencia las observaciones, sin duda desgarbadas, que hemos expuesto en los párrafos anteriores. 